\title{
Morphometry and kinematics of landslides inferred from precise DTMs in West Belgium
}

\section{O. Dewitte and A. Demoulin}

Department of Physical Geography and Quaternary, University of Liège, Allée du 6 Août, 2, Sart Tilman (Bât. B11), 4000 Liège, Belgium

Received: 17 September 2004 - Revised: 8 February 2005 - Accepted: 21 February 2005 - Published: 3 March 2005

Part of Special Issue "Landslides and debris flows: analysis, monitoring, modeling and hazard"

\begin{abstract}
The Flemish Ardennes (W Belgium) are known to be affected by deep-seated landslides. The assessment of the landslide reactivation hazard requires understanding the driving processes and delimiting precisely not only the landslide boundaries but especially that of their most active parts.

Precise 3D models of 13 landslides were produced by digital stereophotogrammetry using aerial photographs of different dates. Dealing with photographs at the scale 1:25000 or larger, we obtained for each model an accuracy better than $0.5 \mathrm{~m}$.

As a first result, the main size parameters of the landslides (width, length, depth, volume, ...) are easily computed.

Moreover, the obtained DTMs may be subtracted from each other in order to determine the apparent vertical displacement of each pixel during the interval of time considered. Provided that more than 2 epochs are documented, such DTMs not only supply precise information about distribution and style of the landslide activity but may also point to temporal variations in this activity.

The subtraction of DTMs allows us to give an estimation of the volume of the "uplifted" and "collapsed" terrains between two epochs.
\end{abstract}

\section{Introduction}

The assessment of the landslide (re)activation hazard requires understanding the driving processes and delimiting precisely not only their boundaries and but especially that of their most active parts.

The first step of this study consisted in producing precise DTMs of 13 landslides of the Flemish Ardennes (W Belgium) in order to determine their morphometric parameters (length, height, volume).

In order to include some kinematic information within a landslide hazard susceptibility map, we also tried to estimate

Correspondence to: O. Dewitte

(odewitte@ulg.ac.be) landslide motion in the medium term (i.e. a few decades) by comparing precise landslide topography reconstructions at different epochs. Moreover, this technique allows us to estimate the mass volumes involved in reactivation.

As shown by Kerle (2002) it is very important to use reliable DTMs. This is why we had to produce our own DTMs, since the accuracy of the available topographical maps and commercial DTMs of the area is not sufficient.

\section{Study area}

Two hilly regions are known to be affected by deep-seated landslides in Belgium, respectively the Pays de Herve to the east (Demoulin and Pissart, 2001; Demoulin et al., 2003) and the Flemish Ardennes to the west of Belgium (VanmaerckeGottigny, 1980; Vanpaemel et al., 2000; Ost et al., 2003; Van Den Eeckhaut et al., 2005). The Flemish Ardennes (Fig. 1) is a landslide-prone area of about $420 \mathrm{~km}^{2}$ in which 135 deepseated landslides have been mapped by Ost et al. (2003) and Van Den Eeckhaut et al. (2005). The Flemish Ardennes has altitudes ranging between 20 and $150 \mathrm{~m}$. This study focuses on two hills situated along the river Schelde close to the town of Oudenaarde (Figs. 1 and 2). These 60-m-high hills culminate between 75 and $85 \mathrm{~m}$. In the north, the Leupegem hill is affected by 3 landslides. To the south, 10 landslides developed on the slopes of the Rotelenberg hill.

These 13 landslides extend in subhorizontal (dip to the north $<1^{\circ}$ ) Eocene sediments composed of alternating clays and clayey sands on which a perched water table can develop. Within these formations, the Aalbeke Member consists of 10-m-thick homogeneous blue massive clays, and has been recognized as the layer most sensitive to landsliding (Fig. 2).

\section{Methodology}

Several morphological features (fresh scarps, tilted trees) point to recent reactivations of the landslides. However, the displacements generally do not exceed a few meters, so that 


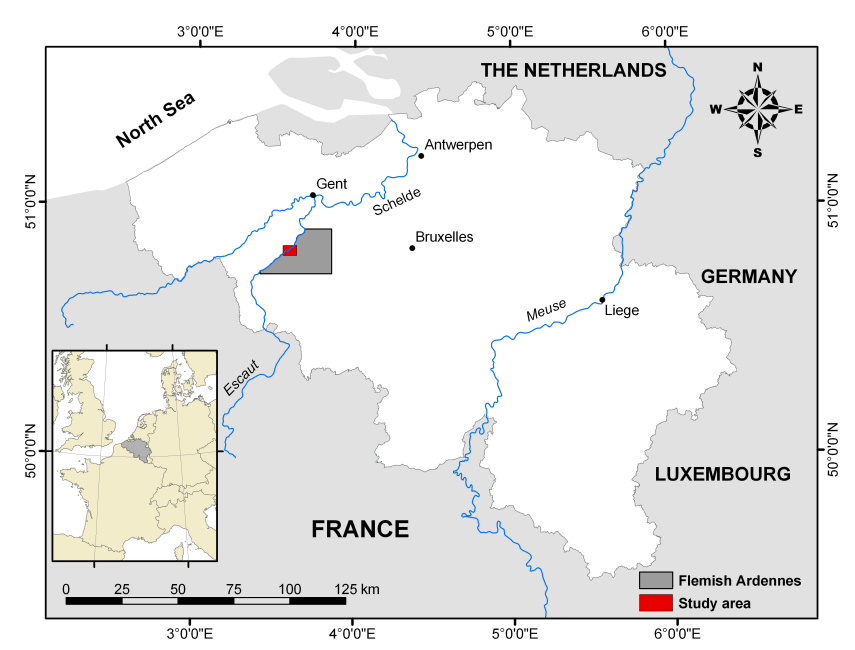

Fig. 1. Location map of the study area.

Table 1. Main characteristics of the photograph negatives used for the digital photogrammetry and overall RMS error at each DTM.

\begin{tabular}{lccc}
\hline Aerial photographs & 1996 & 1973 & 1952 \\
\hline Date & 15 April & 27 April & 17 April \\
Scale & $\sim 1: 20500$ & $\sim 1: 18500$ & $\sim 1: 25000$ \\
DTMs RMS error $(\mathrm{cm})$ & 48 & 39 & 64 \\
\hline
\end{tabular}

DTMs with a vertical accuracy better than $1 \mathrm{~m}$ are needed to map them correctly.

Precise DTMs of the 13 landslides have been obtained by digital stereophotogrammetry using aerial photographs at various image scales between 1:18 500 and 1:25000 of three different periods (Table 1). The system used to construct the DTMs is the LH Systems SOCET SET digital photogrammetric software. The photograph negatives were scanned with an LH Systems DSW 300 precision scanner with a pixel resolution of $12.5 \mu \mathrm{m}$ that corresponds to a ground resolution of approximately 20 to $30 \mathrm{~cm}$. The interior orientation was performed by using the parameters of the camera established by the geometric calibration. These include the location of the principal point, the focal length and the radial distortion. We used the fiducial marks imaged on each photo to relate an image point to this calibrated geometry. The final accuracy of the interior orientation is higher than $10 \mathrm{~cm}$, so that the RMS error of this orientation will not act significantly upon the final accuracy of the stereomodels.

The aerotriangulation of the obtained digital photos was carried out by using the bundle block adjustment method. It is an iterative method based on the use of photo coordinates as observations thanks to what the relative orientation and the absolute orientation are obtained simultaneously (Kraus and Waldhäusl, 1994). The absolute orientation of the block adjustment requires the use of ground control points. Moreover, it must be accurate enough to reflect the actual state of the ground surface. The block adjustment accuracy was

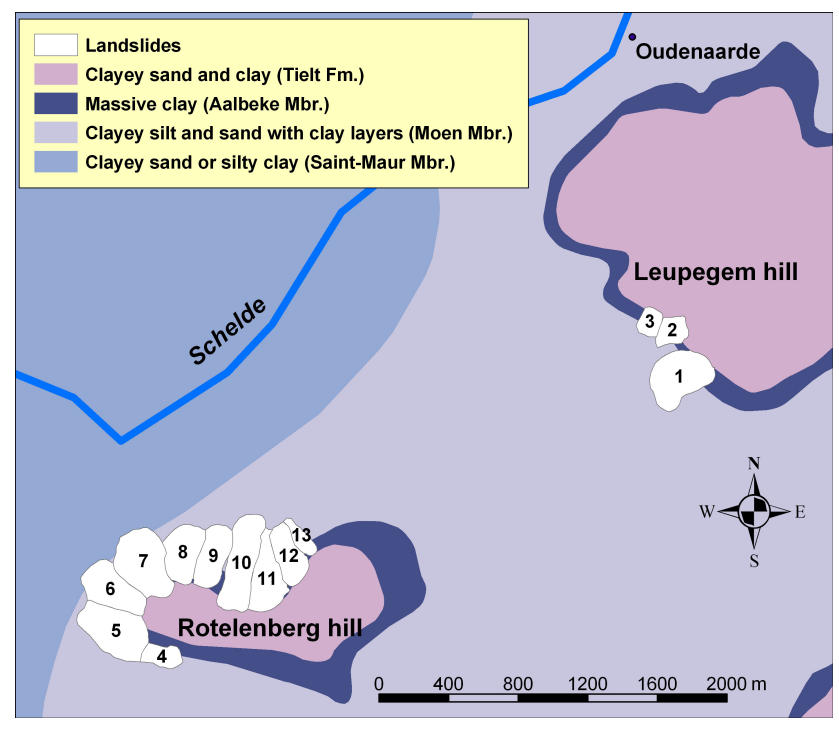

Fig. 2. Location of the landslides of the Leupegem and Rotelenberg. The boundaries of the 13 landslides are shown in white with the lithology.

evaluated using check points with known coordinates, but not used as control in the solution. About 25 ground control points and check points acquired by global positioning system (GPS) were used for the adjustment. The measurements were carried out by differential GPS in rapid static mode involving baselines of a few $\mathrm{km}$ length. The uncertainty on the baseline components (N, E, and Up) is of $\sim 2-3 \mathrm{~cm}$. Absolute positioning of the control and check points relies on the inclusion of five IGN points of known coordinates within the GPS network. The final uncertainty on the coordinates of the control and check points do not exceed $10 \mathrm{~cm}$, thus remaining far below that of the block adjustment. We built firstly the stereomodel of the epoch 1996. The two other stereomodels were then constructed by including the orientation parameters of 1996. The global RMS error obtained range between $\sim 20 \mathrm{~cm}$ and $55 \mathrm{~cm}$ for the three stereomodels.

Since the automatic terrain extraction methods within SOCET SET were not able to provide sufficiently accurate DTM in many places, especially in the numerous forested areas of the study area, the stereoscopic data capture of spot heights (ground points) and breaklines (scarps, roads, water bodies) on the landscape surface was performed by eye, by manually adjusting a floating mark until it touched the surface viewed in stereo. The spot heights were extracted approximately every 5 to $10 \mathrm{~m}$. These spot heights and breaklines (which depict abrupt changes in elevation and increase the accuracy of the DTMs) were interpolated with SURFER 8.0 by kriging for a DTM generation in the form of a $2 \mathrm{~m} \times 2 \mathrm{~m}$ grid. The kriging parameters used to interpolate the DTMs were determined on the basis of variograms. The mean errors of the kriging interpolations are $\sim 40 \mathrm{~cm}$.

The DTMs were then measured and subtracted from each other to describe the morphology and the kinematics of the landslides. 
Table 2. Morphometric measurements obtained from the 1996 DTM for the 13 landslides of the Leupegem and Rotelenberg hills.

\begin{tabular}{|c|c|c|c|c|c|c|c|c|c|c|c|c|c|c|c|c|}
\hline Landslide & $\begin{array}{c}\mathbf{A} \\
\left(\mathrm{m}^{2}\right) \\
\end{array}$ & $\begin{array}{c}\mathbf{h} \\
(\mathrm{m}) \\
\end{array}$ & $\begin{array}{l}\mathbf{H} \\
(\mathrm{m}) \\
\end{array}$ & $\begin{array}{l}\mathbf{a} \\
\left({ }^{\circ}\right) \\
\end{array}$ & $\begin{array}{c}\mathbf{L} \\
(\mathrm{m})\end{array}$ & $\begin{array}{l}\text { Ld } \\
(\mathrm{m})\end{array}$ & $\begin{array}{l}\mathbf{L r} \\
(\mathrm{m})\end{array}$ & $\begin{array}{l}\text { Wd } \\
(\mathrm{m}) \\
\end{array}$ & $\begin{array}{l}\mathbf{W r} \\
(\mathrm{m})\end{array}$ & $\begin{array}{c}\operatorname{Dr}(\mathbf{0 . 1 5}) \\
(\mathrm{m}) \\
\end{array}$ & $\begin{array}{c}\operatorname{Dr}(\mathbf{0 . 3 3}) \\
(\mathrm{m}) \\
\end{array}$ & $\begin{array}{c}\text { Volr }(\mathbf{0 . 1 5}) \\
\left(10^{3} \mathrm{~m}^{3}\right) \\
\end{array}$ & $\begin{array}{c}\text { Volr }(\mathbf{0 . 3 3}) \\
\left(10^{3} \mathrm{~m}^{3}\right) \\
\end{array}$ & $\begin{array}{c}\text { Vold }(\mathbf{0 . 1 5}) \\
\left(10^{3} \mathrm{~m}^{3}\right) \\
\end{array}$ & $\begin{array}{c}\text { Vold }(\mathbf{0 . 3 3}) \\
\left(10^{3} \mathrm{~m}^{3}\right) \\
\end{array}$ & S.F. \\
\hline 1 & 87696 & 9 & 52 & 8 & 372 & 359 & 266 & 262 & 226 & 40 & 88 & 1255 & 2761 & 1965 & 4323 & 0.57 \\
\hline 2 & 26735 & 8 & 31 & 8 & 236 & 208 & 147 & 162 & 169 & 22 & 48 & 286 & 629 & 388 & 853 & 0.36 \\
\hline 3 & 22617 & 9 & 27 & 8 & 185 & 159 & 119 & 148 & 122 & 18 & 39 & 136 & 300 & 222 & 488 & 0.63 \\
\hline 4 & 25275 & 7 & 21 & 9 & 133 & 113 & 89 & 243 & 196 & 13 & 29 & 123 & 271 & 193 & 425 & 0.57 \\
\hline 5 & 94730 & 9 & 50 & 8 & 345 & 329 & 241 & 238 & 200 & 36 & 79 & 911 & 2005 & 1478 & 3252 & 0.62 \\
\hline 6 & 72652 & 8 & 57 & 8 & 408 & 393 & 253 & 140 & 117 & 38 & 83 & 588 & 1293 & 1089 & 2395 & 0.85 \\
\hline 7 & 93422 & 8 & 62 & 8 & 439 & 429 & 275 & 173 & 175 & 41 & 91 & 1043 & 2295 & 1600 & 3521 & 0.53 \\
\hline 8 & 60466 & 8 & 53 & 9 & 352 & 338 & 240 & 186 & 161 & 36 & 79 & 726 & 1597 & 1182 & 2601 & 0.63 \\
\hline 9 & 55235 & 7 & 47 & 7 & 375 & 361 & 231 & 164 & 156 & 35 & 76 & 654 & 1439 & 1078 & 2371 & 0.65 \\
\hline 10 & 89755 & 7 & 51 & 5 & 575 & 559 & 318 & 163 & 186 & 48 & 105 & 1482 & 3261 & 2271 & 4996 & 0.53 \\
\hline 11 & 63944 & 9 & 41 & 7 & 357 & 343 & 199 & 214 & 250 & 30 & 66 & 781 & 1717 & 1151 & 2532 & 0.47 \\
\hline 12 & 46188 & 9 & 49 & 8 & 338 & 320 & 200 & 152 & 190 & 30 & 66 & 594 & 1306 & 761 & 1673 & 0.28 \\
\hline 13 & 18932 & 8 & 41 & 9 & 264 & 246 & 155 & 88 & 84 & 23 & 51 & 158 & 347 & 265 & 582 & 0.68 \\
\hline \multirow[t]{2}{*}{ Mean } & 58281 & 8 & 45 & 8 & 337 & 320 & 210 & 179 & 172 & 32 & 69 & 672 & 1479 & 1049 & 2309 & 0.57 \\
\hline & $51000^{*}$ & & & $7 *$ & $200^{*}$ & & & $*=\mathrm{me}$ & val & or 78 lan & s (Ost et $c$ & 003) & & & & \\
\hline
\end{tabular}

\section{Results}

Six DTMs (3 different dates for each investigated hill) have been produced with an overall RMS error of $\sim 50 \mathrm{~cm}(\mathrm{Ta}-$ ble 1). Figures 3 and 4 show the morphology of the 13 coalescent deep-seated landslides in 1996.

\subsection{Morphometry and static data}

The morphometric parameters presented in Table 2 were either measured directly on the 1996 DTMs, or derived from other parameters.

The landslide area $\mathrm{A}$, the maximum $h$ height of the main scarp and $H$ the height of the landslide (difference in elevation between the crown and the tip of the landslide) were first obtained. As exemplified for a particular landslide of the Leupegem hill (Fig. 5), the morphometric parameters $L, L_{d}$, $L_{r}, W_{d}, W_{r}$ were measured according to the definitions of the IAEG Commission on Landslides (1990).

The travel angle $\alpha$ of a landslide (Cruden and Varnes, 1996) was computed as:

$\alpha=\arctan \frac{H}{L_{h}}$

The total length $L_{h}$ is the horizontal component of the overall runout (or travel distance) of the landslide. The measurement is taken to approximate best the centre-line of the mass movement. $H$ is the vertical component of the overall runout. The travel angle is related to the mobility and the volume of the landslide (Hutchinson, 1988; Corominas, 1996).

The ground-surface dimensions $W_{d}$ and $L_{d}$ of the displaced material, and $W_{r}$ of the surface of rupture were measured directly on the DTM. The measurements of $L_{r}$ present more difficulties and are less accurate because the toe of the surface of rupture is not exposed. Cruden (1986) showed that its position could sometimes be estimated from graphical extrapolation of the main scarp supported by measurements of displacements within the slipped mass. This technique as well as another proposed by Carter and Bentley (1985) also provide and estimation of $D_{r}$, the depth of the rupture surface, and $D_{d}$, the depth of the displaced mass. However, site investigations provide generally a more precise location of slip surfaces (Hutchinson, 1983). Due to lack of information, $L_{r}$ was directly estimated on the DTMs by taking the original slopes around the landslides into account.

The ratio between depth and length of the surface of rupture $\left(D_{r} / L_{r}\right)$ is one of the most used indexes to describe landslide processes (Skempton and Hutchinson, 1969; Crozier, 1973; Soeters and Van Westen, 1996). The $D_{r}$ calculation is based on the Skempton and Hutchinson (1969)'s results showing that rotational soil slides generally exhibit a ratio, $D_{r} / L_{r}$, between 0.15 and 0.33 .

The initial volume of material before the landslide moved, $\mathrm{Vol}_{r}$ (Table 2) was computed as (Cruden and Varnes, 1996):

$\mathrm{Vol}_{r}=\frac{1}{6} \pi D_{r} \times W_{r} \times L_{r}$

The post-motion volume of the displaced material, $\mathrm{Vol}_{d}$ could not be computed with the same accuracy because $D_{d}$ was not known. $\mathrm{Vol}_{d}$ values (Table ) were obtained by considering that $D_{d}=D_{r}$. Therefore, the volume of the displaced material is given here by

$\mathrm{Vol}_{d}=\frac{1}{6} \pi D_{r} \times W_{d} \times L_{d}$

adapted from the equation given by (WP/WLI, 1990). 


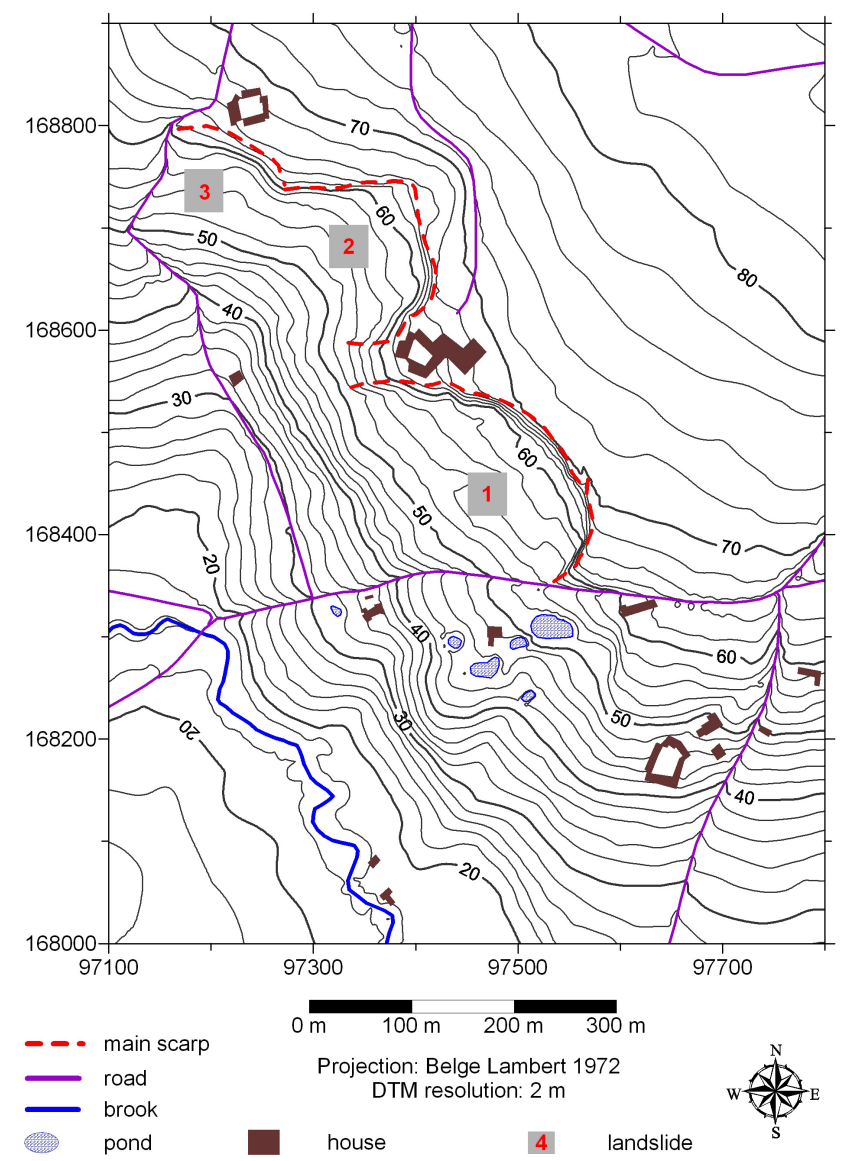

Fig. 3. The 1996 DTM of the Leupegem hill with location of the landslides 1, 2 and 3.

$\mathrm{Vol}_{r}$ and $\mathrm{Vol}_{d}$ were computed with the two extremes values of $D_{r}$ found by Skempton and Hutchinson (1969): $D_{r}=0.15 L_{r}$ and $0.33 L_{r}$.

Mass movement is usually associated with dilation and volume increase of the displaced material. The percentage of increase in the volume is called swell factor (S.F. in Table 2).

The average values of $\mathrm{A}$ and of $\alpha$ in Table 2 are similar to those found by Ost et al. (2003) for 78 landslides. However, the total length $L$ of the landslides selected for this study is greater than the average $L$ of all landslides of the Flemish Ardennes.

Several studies (Hutchinson, 1988; Nicoletti and SorrisoValvo, 1991; Corominas, 1996) showed that, whatever the mechanism of motion, all movements experience a reduction of travel angle with an increasing volume. Moreover, Corominas (1996) showed that rotational slides display the lowest travel angle values. The travel angle values computed here correspond to those found by Corominas (1996) for rotational slides with similar volumes. We also observe that the biggest landslide of our dataset, landslide 10, has the lowest travel angle and that two of the smallest landslides (landslides 4 and 13) show the highest values.

Comparing the volumes before and after landsliding, a
$64 \%$ swell factor is obtained. This mean value is slightly lower than the 67\% proposed by Church (1981) for solid rocks that have been mechanically excavated but is over the Nicoletti and Sorriso-Valvo (1991) 33\% for rock avalanches. Unfortunately, as already stated by Cruden and Varnes (1996), more precise information on swell factors is as yet unavailable. In addition, the method used for estimating landslide volumes is inaccurate in the case topography diverts the displaced material from rectilinear path. Then, more elaborated surveys and analysis are necessary (Nicoletti and Sorriso-Valvo, 1991).

Our results require several comments:

- Some parameters values such as $L_{r}, L$ and $L_{d}$ are to some extent questionable since they depend on the precise location of particular points in the landslide (obtained by DTM interpretation coupled with field observations).

- All comments rely on the hypothesis that the landslides are single rotational slides. However, landslides 7, 8, 9 are more probably multiple rotational landslides. Slopes of rotational movements generally range between $13^{\circ}$ and $40^{\circ}$ (Skemton and Hutchinson, 1969; Crozier, 1973; Soeters and Van Westen, 1996). With a mean value of $8^{\circ}$, the slopes of our landslides are more typical of successive slides (Skemton and Hutchinson, 1969; Hutchinson, 1988; Buma and Van Ash, 1996). However, the other dimensions of successive slides are generally much lower than what we compute here. For example, in gentle slopes of $\sim 8^{\circ}$ in stiff London Clay coastal cliffs, Hutchinson (1988) reported individual slip units with a ground slope length mostly around 10 to $20 \mathrm{~m}$ and with failure surface depths $\leq 5 \mathrm{~m}$. Similar slopes are also reported for slab slides (Hutchinson, 1988; Ibsen et al., 1996). The parameter values calculated for the 13 landslides of the Leupegem and the Rotelenberg hills indicate that they are probably compound slides with a $D_{r} / L_{r}$ ratio smaller than that of rotational slides, whereas their width would be generally greater (Hutchinson, 1988; Soeters and Van Westen, 1996)

However, we clearly need to measure more landslides before drawing firm conclusions especially since no geophysical investigation has been performed to locate the slip surface (Hutchinson, 1983; McGuffy et al., 1996).

\subsection{Kinematic data}

The obtained DTMs may be subtracted from each other in order to determine the vertical displacement of each pixel during the considered time interval (Figs. 6 and 7). At the head of the landslides, large apparent vertical motion values generally correspond to the height of the scarps actually retreating. There, the amount of scarp retreat may be fairly approximated by the width of the band of "collapsed" terrains. 


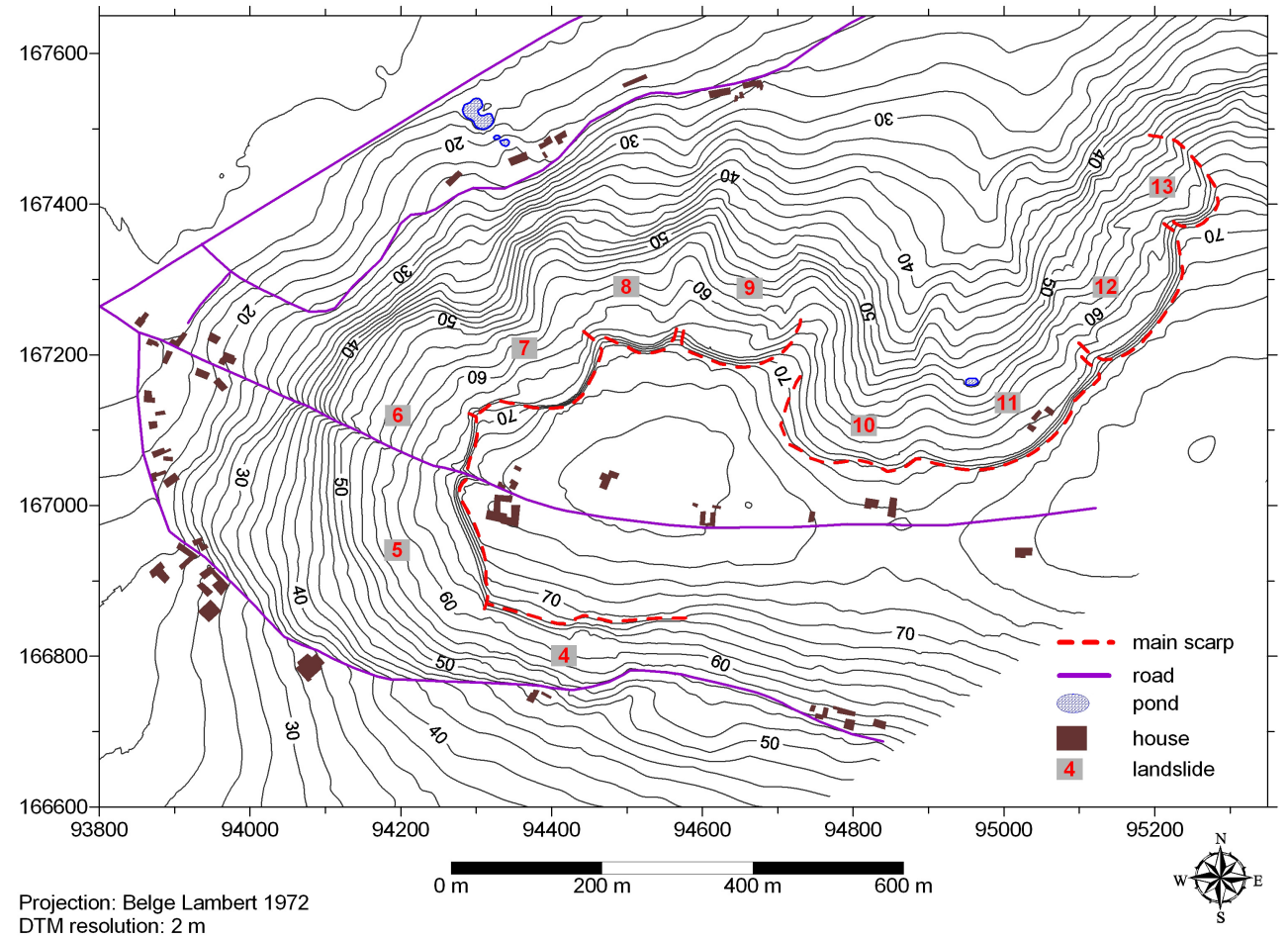

Fig. 4. The 1996 DTM of the Rotelenberg hill with location of the landslides 4 to 13 .

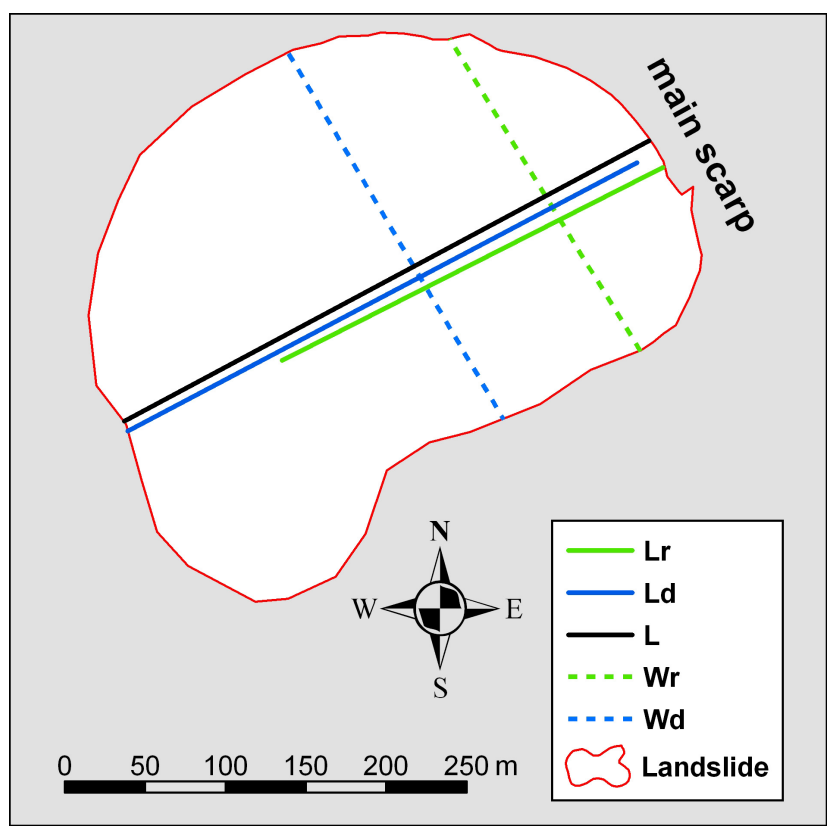

Fig. 5. Definition of five dimensions of the landslide 1. $L$, total length; $L_{d}$, length of the displaced mass; $L_{r}$, length of the rupture surface; $W_{d}$, width of the displaced mass; $W_{r}$, width of the rupture surface.

From 1952 to 1996, landslide 6 was active (Fig. 6), with an observed mass movement typical of a rotational slide. During the 1952-1973 interval (Fig. 6A), the downslope uplifted part was more important than the upslope collapsed part. In the time from 1973-1996, the relation becomes op- posite (Fig. 6B). This could be related perhaps with inertia phenomena (Van Westen and Getahun, 2003) associated with the long-lasting evolution of the landslide since before 1952. At the head of the landslide (Fig. 6C), apparent vertical motions of up to $4 \mathrm{~m}$ correspond mainly to lateral displacement of the scarp. The two collapsed parts 1 and 2 (Fig. 6C) in the zone of depletion suggest multiple rotational landsliding. This landslide is presently still active (Dewitte, 2004).

In favourable cases, locating the moving areas allows the identification of the stable slopes around a landslide. They can be then interpolated in order to recreate the original slope on which the landslide has developed. For instance, elevation changes within landslide 1 between 1996 and the time before landsliding show again a typical rotational process (Fig. 7). This is significant especially owing to the representativeness of landslide 1 for all landslides of the Flemish Ardennes (Dewitte and Demoulin, 2003; Ost et al., 2003). Moreover, the total motion since the onset of landsliding is considered here.

As already stressed by Weber and Hermann (2000) a DTM subtraction between two epochs cannot provide the overall volume of the displaced mass as measured in Sect. 4.1 but, this difference allows an estimation of the volume of the "uplifted" or "collapsed" terrain between the two epochs (Table 3).

The difference between the DTMs of 1996 and 1952 exhibits a slightly positive volume balance for landslide 1 (Table 3.1) whereas a negative balance is observed for the whole of the 13 landslides (Table 3.2). The volume increase of landslide 1 is probably due to the combination of episode of intense reactivation in 1995 (Ost et al., 2003) and the deposition of 50 trucks load of soil (Dewitte and Demoulin, 2003). 


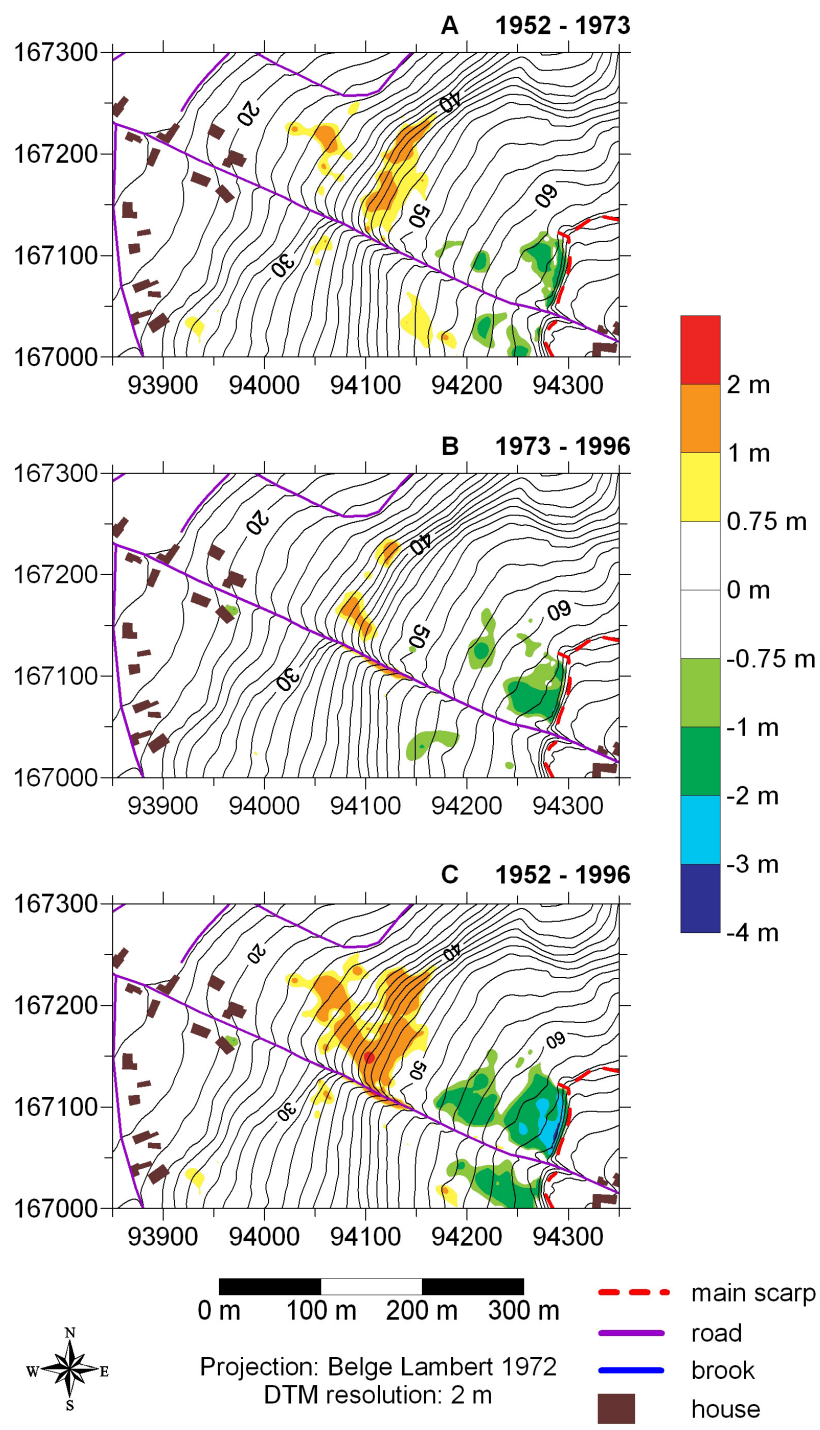

Fig. 6. Elevation changes within the landslide 6. (A): from 1952 to 1973; (B): from 1973 and 1996; (C): from 1952 to 1996. The movements in excess of $1 \sigma$ uncertainty are represented.

Subtracting the DTM with the original slope from that of 1996 provides an estimation of the total volume of the "uplifted" and the "collapsed" terrains (Fig. 7 and Table 3.3). These volumes are two times bigger than for the period 1952-1996, suggesting that a ground movement of at least the same importance that the one observed between 1952 and 1996 had already taken place before 1952 .

The volume increase associated with motion-dependent dilation of the displaced material is not observed here for most landslides (Table 3.2). This may be explained by the old age, probably many hundreds of years, of the landslides, which left enough time for the compaction of the slipped masses. By comparison, Brueckl et al. (2004) interpreted a loss of volume as resulting from the compaction of a moving rock mass by $1.5 \%$ during a period of 34 years. Moreover, erosion of the "uplifted" volume in the downslope part of the landslide, notably through active suffusion, must induce a net loss of volume within the landslide.

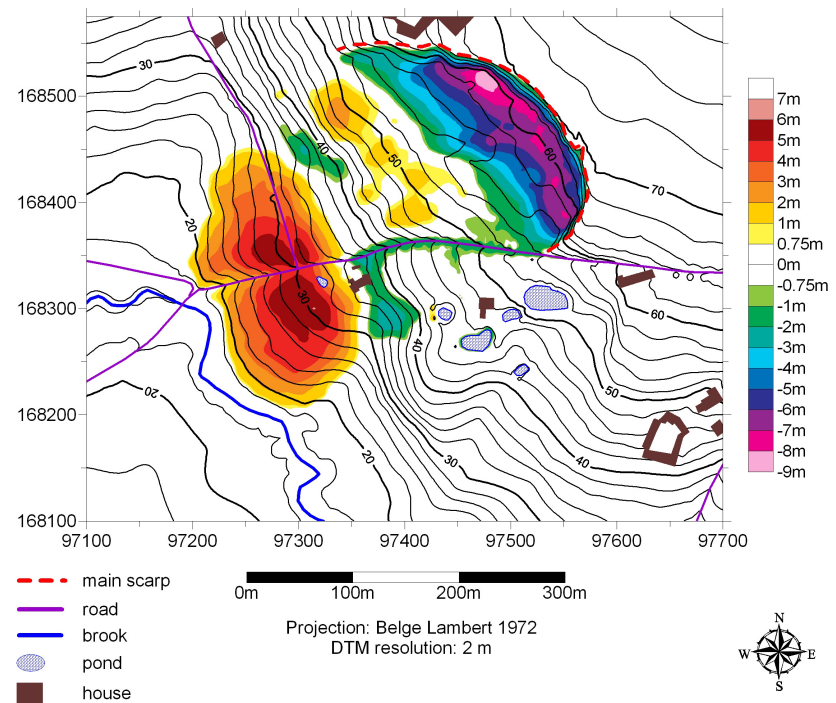

Fig. 7. Elevation changes within the landslide 1 between 1996 and the time before landsliding. The movements in excess of $1 \sigma$ uncertainty are represented.

Table 3. Positive ("uplifted") and negative ("collapsed") volumes relating to various epochs obtained by subtraction of DTMs. Row 1: Evolution of landslide 1 from 1952 to 1996. Row 2: Same for the sum of all landslides of the Leupegem and Rotelenberg hills. Row 3: Volume differences in landslide 1 between 1996 and the time before landsliding occurred.

\begin{tabular}{lc}
\hline 1 Landslide 1 (1996-1952) & $\left(\mathrm{m}^{3}\right)$ \\
\hline Positive volume & 46838 \\
Negative volume & 45848 \\
Net volume & 990 \\
\hline 2 Landslides 1-13 (1996-1952) & $\left(\mathrm{m}^{3}\right)$ \\
\hline Positive volume & 133562 \\
Negative volume & 142421 \\
Net volume & -8859 \\
\hline 3 Landslide 1 (1996 - orignal slope) & $\left(\mathrm{m}^{3}\right)$ \\
\hline Positive volume & 101127 \\
Negative volume & 105559 \\
Net volume & -4432 \\
\hline
\end{tabular}

\section{Conclusions}

Thanks to the use of precise DTMs, the main morphometric parameters of the landslides have been measured with a high accuracy and so we were able to understand better their structure and driving processes. Moreover, by subtracting the DTMs from each other, we also localised the active parts of the landslides between 1952 and 1996 and estimated the volume of the "uplifted" and "collapsed" parts.

The field observations show that some of the reactivation movements are due to the development of cultivated areas upstream of the main scarps. Mainly in winter, the bare soils favour flow concentration toward the landslides. It has been observed that the reactivation of the landslide 1 (Figs. 3 and 
7) in February 1995 was partly caused by such an important runoff. A detailed study of the various causes of landslide reactivation in the Flemish Ardennes is currently in progress.

Finally, as a next step of the research, we will need now to define a standardized representation of such kinematic data in order to use them in the production of landslide susceptibility maps focusing on the hazard related to reactivation of existing landslides.

Acknowledgements. We thank A. Carrara for his useful comments on the first draft of the article.

Edited by: G. B. Crosta

Reviewed by: A. Carrara

\section{References}

Brueckl, E., Brunner, F. K., and Kraus, K.: The kinematic of deepseated mass movement derived from geophysical, GPS and photogrammetric data, Geophys. Res. Abstr., 6, 2004.

Buma, J. and van Asch, T.: Slide (rotational), in: Landslide Recognition, edited by: Dikau, R., Brunsden, D., Schrott, L., and Isben, M.-L., Identification, Movement and Causes, John Wiley \& Sons, Chichester, 42-61, 1996.

Carter, M. and Bentley, S. P.: The geometry of slip surfaces beneath landslides: prediction from surface measurements, Can. Geotech., 22, 234-238, 1985.

Church, H. K.: Excavation Handbook, McGraw-Hill, New-York, N. Y., 1024, 1981.

Corominas, J.: The angle of reach as a mobility index for small and large landslides, Can. Geotech., 33, 260-271, 1996.

Crozier, M. J.: Techniques for the morphometric analysis of landslips, Z. Geomorph., 17, 78-101, 1973.

Cruden, D. M.: Discussion of Carter, M. and Bentley, S. P., 1985, The geometry of slip surfaces beneath landslides: prediction from surface measurements, Can. Geotech., 23, 94, 1986.

Cruden, D. M. and Varnes, D. J.: Landslide Types and Processes, in: Landslides: Investigation and Mitigation, Transportation Research Board, edited by: Turner, A. K. and Schuster, R. L., Special Report 247, National Research Council, National Academy Press, Washington D. C., 36-75, 1996.

Demoulin, A. and Pissart, A.: Past landslides in the Verviers (E Belgium) area: climate- or earthquake-induced features?, Cahiers du Centre européen de géodynamique et de séismologie, 18, 203216, 2001

Demoulin, A., Pissart, A., and Schroeder, C.: On the origin of late Quaternary paleolandslides in the Liège (E Belgium) area, Int. J. E. Sci., 92, 795-805, 2003.

Dewitte, O.: Construction and analysis of precise DTMs of landslides in Belgium, Geohys. Res. Abstr., 6, 2004.

Dewitte, O. and Demoulin, A.: Combined digital photogrammetry and GPS approaches of landslides evolution in Belgium, Geophys. Res. Abstr., 5, 2003.

Hutchinson, J. N.: Methods of locating slip surfaces in landslides. Bulletin of the Association of Engineering Geologist, 20, 3, 235$252,1983$.

Hutchinson, J. N.: General Report: Morphological and geotechnical parameters of landslides in relation to geology and hydrogeology, in: Proceedings of the Fifth International Symposium on Landslides, edited by: Bonnard, C., Balkema, Rotterdam, 3-35, 1988.
IAEG Commission on Landslides: Suggested nomenclature for landslides. Bulletin of the International Association of Engineering Geology, 41, 13-16, 1990.

Ibsen, M.-L., Brunsden, D., Bromhead, E., and Collison. A.: Slide (translational), Slab slide, in: Landslide Recognition, edited by: Dikau, R., Brunsden, D., Schrott, L., and Isben, M.-L., Identification, Movement and Causes, John Wiley \& Sons, Chichester, 78-84, 1996.

Kerle, N.: Volume estimation of the 1998 flank collapse at Casita volcano, Nicaragua: a comparison of photogrammetric and conventional techniques, Earth. Surf., 27, 759-772, 2002.

Kraus, K. and Waldhäusl. P.: Photogrammetrie, band 1: Grundlagen und Standardverfahren, $5^{\text {th }}$ edition, Dümmlers Verlag, Bonn, 1994, French translation: Grussenmeyer, P. and Reis, O.: Manuel de photogrammétrie: principes et procédés fondamentaux, Hermes, Paris, 407, 1998.

McGuffy, V. C., Modeer, V. A. and Turner, A. K.: Subsurface exploration, in: Landslides: Investigation and Mitigation, Transportation Research Board, edited by: Turner, A. K. and Schuster, R. L., Special Report 247, National Research Council, National Academy Press, Washington D.C., 231-277, 1996.

Nicoletti, P. G. and Sorriso-Valvo, M.: Geomorphic controls of the shape and mobility of rock avalanches, Geol. S. Am. B., 103, 10, 1365-1373, 1991.

Ost, L., Van Den Eeckhaut, M., Poesen, J., and VanmaerckeGottigny, M. C.: Characteristics and spatial distribution of large landslides in the Flemish Ardennes (Belgium), Z. Geomorph., 47, 329-350, 2003.

Skepton, A. W. and Hutchinson, J. N.: Stability of natural slopes and embankment foundations, in: Proceedings of the Seventh International Conference on Soil Mechanics and Foundation Engineering, Sociedad Mexicana de Mecána de Suelos, Mexico City, State of the Art Volume, 291-340, 1969.

Soeters, R. and Van Westen, C. J.: Slope instability recognition, analysis, and zonation, in: Landslides: Investigation and Mitigation, Transportation Research Board, edited by: Turner, A. K. and Schuster, R. L., Special Report 247, National Research Council, National Academy Press, Washington D.C., 129-177, 1996.

Van Den Eeckhaut, M., Poesen, J., Verstraeten, G., Vanacker, V., Moeyersons, J., Nyssen, J., and van Beek, L. P. H.: The effectiveness of hillshade maps and expert knowledge in mapping gold deep-seated landslides, Geomorphology, in press, 2005.

Vanmaercke-Gottigny, M. C.: Landslides as a morphogenetic phenomenon in a hilly region of Flanders (Belgium), in: Assessment of erosion, edited by De Boodt, M. and Gabriels, D., John Wiley and Sons, Chichester, 475-484, 1980.

Vanpaemel, L., Poesen, J., and Vanmaercke-Gottigny, M. C.: Massatransport in de Vlaamse Ardennen: ruimtelijke en temporele dynamiek, De Aardrijkskunde, 3, 51-60, 2000.

Van Westen, C. J. and Getahun, F. L.: Analyzing the evolution of the Tessina landslide using aerial photographs and digital elevation models, Geomorphology, 54, 77-89, 2003.

Weber, D. and Herrmann, A.: Contribution de la photogrammétrie numérique à l'étude spatio-temporelle de versants instables: l'exemple du glissement de Super-Sauze (Alpes-de-HauteProvence), B. Soc. Geol., 171, 6, 637-648, 2000.

WP/WLI: A suggested method for reporting a landslide. Bulletin of the International Association of Engineering Geology, 41, 5-12, 1990. 